\begin{tabular}{ll}
\hline \hline MINING AND METALLURGY INSTITUTE BOR & ISSN: 2334-8836 (Štampano izdanje) \\
UDK: 622 & ISSN: 2406-1395 (Online) \\
\hline
\end{tabular}

UDK: $621.63: 681.325(045)=111$

doi:10.5937/mmeb1704195R

Branislav Rajković, Dragoljub Cvetković, Radmilo Rajković*

\title{
SELECTION OF INDUSTRIAL PROCESS FAN WITH APPLICATION OF SOFTWARE
}

\begin{abstract}
This paper presents the procedure of fan selection by the software ProSelecta2 on the example of an industrial process fan with given technical characteristics. For the selected fan, the detailed technical characteristics are given, as well as a drawing of the fan with built-in dimensions. In brief, the basic alternative options for selecting the fan using this software are explained.

Keywords: industrial process fan, software ProSelecta 2
\end{abstract}

\section{INTRODUCTION}

Process air fans have a wide application in the industry and they represent an important component of equipment and plants in many branches of the process engineering. These fans generate a forced circulation of air that can be used for cooling, drying, ventilation, extracting, combustion in furnaces, etc. The fan manufacturer Nicotra Gebhardt, which is the author of the ProSelecta2 software, has the classified industrial process fans in four series covering the application area for capacity up to $100000 \mathrm{~m}^{3} / \mathrm{h}$, and total pressure rise up to $8000 \mathrm{~Pa}$ [1]. Maximum medium temperature is $300^{\circ} \mathrm{C}$. There are also the fan versions for explosive and dusty environment, as well as various variants of drives, various types of materials and accessories. This paper will be show a fan selection procedure on the example of industrial process fan for clean air with maximum temperature of $35^{\circ} \mathrm{C}$, capacity of $71632 \mathrm{~m}^{3} / \mathrm{h}$ and total pressure rise of $3706 \mathrm{~Pa}$.

\section{EXPERIMENTAL AND RESULTS}

The fan selection starts in the 'Selectioninput data' window (Figure 1) where the criteria for selection are listed. In this case, the industrial process fan of $\mathrm{P} 4 \mathrm{M}$ series was selected. The fans of this series consist of a base frame, spiral housing in a robust steel construction with a single circular axial suction connection, and a rectangular tangential discharge connection, as well as a welded impeller with backward curved blades mounted on the shaft of the electromotordirect drive. In this window you enter the values of the required capacity, the total pressure rise, as well as the density and maximum temperature of medium. It contains the sub-options for the selection of drives, materials and degree of anti-explosion protection. In this case, a direct drive was selected with an electromotor with a frequency inverter for the net frequency of $50 \mathrm{~Hz}$ and arbitrary number of poles, non-alloy steel as a material and a standard fan version without anti-explosion protection. For the given pa-

\footnotetext{
* Mining and Metallurgy Institute Bor, e-mail: branislav.rajkovic@irmbor.co.rs
} 
rameters, the program gives the listing of fan with the P4M-T3B62-RBC label was fans from which the user selects one fan. A selected here.

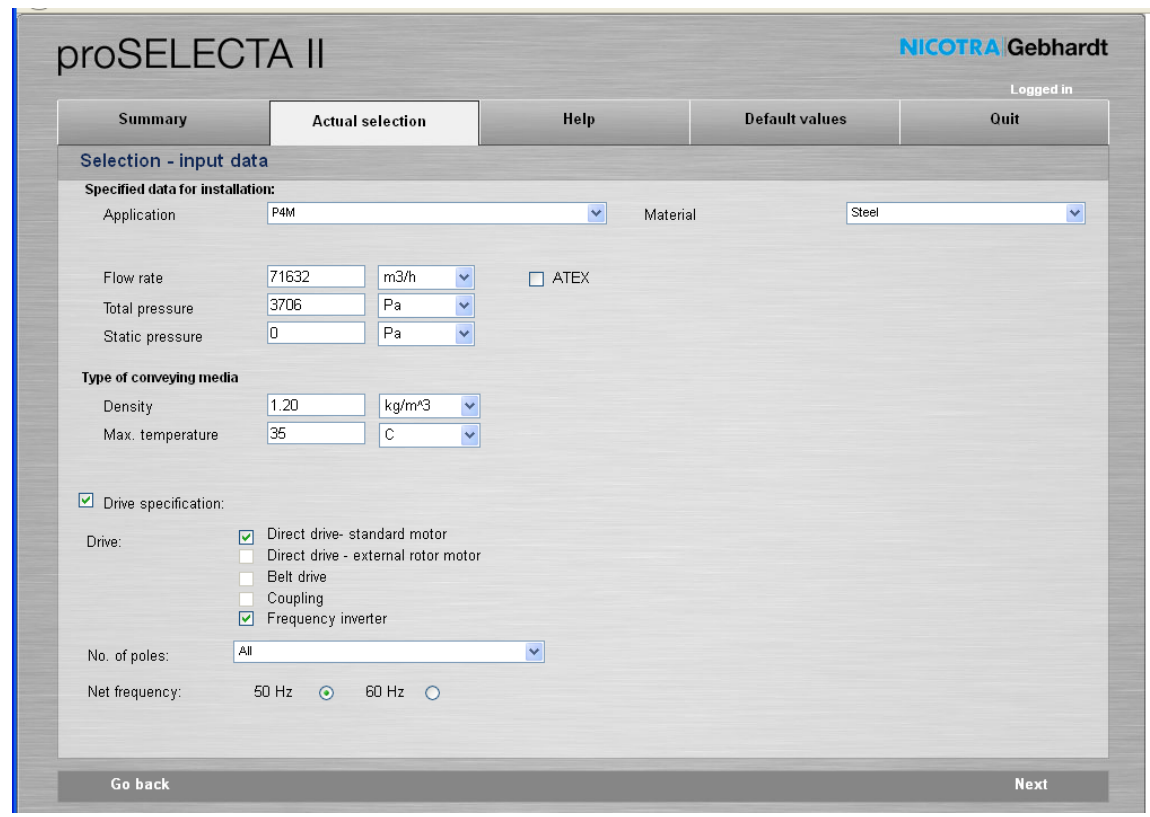

Figure 1 Criteria for the fan selection-window "Selection-input data"

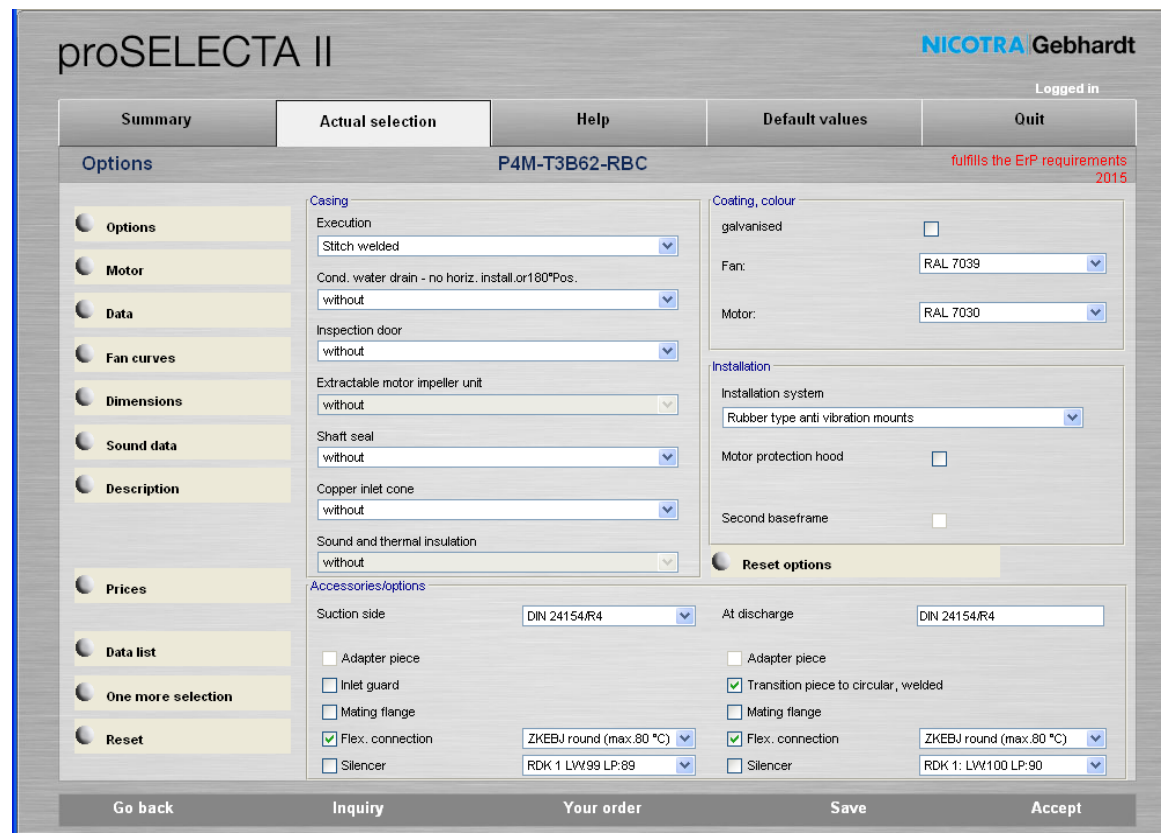

Figure 2 Options for the fan selection-window "Options " 
The fan selection is continued selecting the corresponding equipment of selected fan in the 'Options' window (Figure 2). In this window, the user has the ability to define the characteristics of the housing, type of anti-corrosion coating, methods of installation and options regarding suction and discharge connection. In this case, the options related to the selection of a flexible connection, i.e. a compensator on suction connection and discharge connection, as well as a transition piece from rectangular to circular on a discharge connection are checked, while all other options are left as default. The method of installing the fan here is via rubber type anti-vibration pads.

In the "Motor selection" window, the user has the option of selecting an electromotor from the list of electro motors. An electromotor marked ACM315 M-6/HE was selected here.
The angular position of fan discharge connection and rotation direction is defined in the 'Inquiry' window.

Having completed the selection of fan and electromotor the software shows output data in the windows "Data", "Fan curves", "Dimensions", "Sound data" and "Description". Technical characteristics of the fan are given in the 'Data' window at the operating point and at the best efficiency point. Operating curves of the total pressure rise or static pressure rise, efficiency and power consumption on shaft in relation to volumetric flow rate are given in the 'Fan curves' window. Figure 3 shows a diagram of the total pressure rise, efficiency and power consumption on a fan shaft in the function of volumetric flow rate for a fan speed of $1185 \mathrm{rpm}$ and air density of $1.2 \mathrm{~kg} / \mathrm{m}^{3}$.
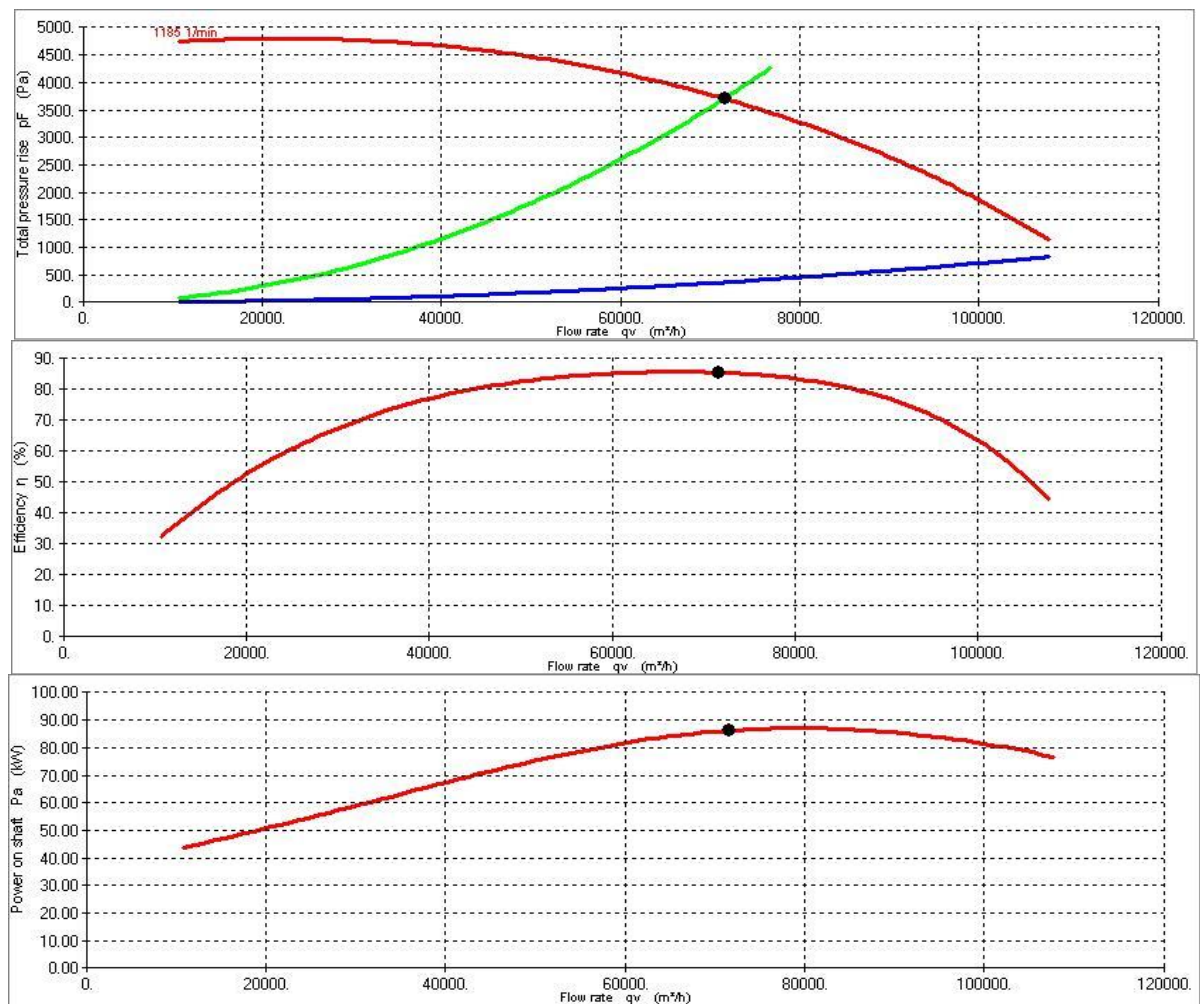

Figure 3 Total pressure rise, efficiency and power consumption on a fan shaft in the function of volumetric flow rate of the fan P4M-T3B62-RBC 
A drawing with the built-in dimensions of the fan is given in the 'Dimensions' window. The fan sketch is shown in Figure 4. In the 'Sound data' window, the values of noise level in $\mathrm{db}$ for various frequencies are given (see Table 1). In the 'Description' window, a technical description of the fan is given. Using option 'Print inquiry' in the 'Inquiry' window, the user has the ability to print all output data. The output data with the technical characteristics of the fan and electromotor are shown in Table 2.

Table 1 Noise level for the fan P4M-T3B62-RBC

\begin{tabular}{|l|c|c|c|c|c|c|c|c|c|c|c|}
\hline & LWA & $\begin{array}{c}\mathbf{6 3} \\
{[\mathbf{H z}]}\end{array}$ & $\begin{array}{c}\mathbf{1 2 5} \\
{[\mathbf{H z}]}\end{array}$ & $\begin{array}{c}\mathbf{2 5 0} \\
{[\mathbf{H z}]}\end{array}$ & $\begin{array}{c}\mathbf{5 0 0} \\
{[\mathbf{H z}]}\end{array}$ & $\begin{array}{c}\mathbf{1 0 0 0} \\
{[\mathbf{H z}]}\end{array}$ & $\begin{array}{c}\mathbf{2 0 0 0} \\
{[\mathbf{H z}]}\end{array}$ & $\begin{array}{c}\mathbf{4 0 0 0} \\
{[\mathbf{H z}]}\end{array}$ & $\begin{array}{c}\mathbf{8 0 0 0} \\
{[\mathbf{H z}]}\end{array}$ & $\begin{array}{c}\text { LPA } \\
(\mathbf{1 m})\end{array}$ & \\
\hline $\begin{array}{l}\text { Casing brake } \\
\text { trough level } \\
\text { L_2: }\end{array}$ & 100 & 70 & 85 & 90 & 95 & 94 & 93 & 89 & 85 & 83 & $\mathrm{~dB}$ \\
\hline $\begin{array}{l}\text { Level for } \\
\text { free intake } \\
\text { L_5: }\end{array}$ & 110 & 86 & 100 & 102 & 105 & 103 & 101 & 98 & 93 & 100 & $\mathrm{~dB}$ \\
\hline $\begin{array}{l}\text { Level for } \\
\text { free outlet } \\
\text { L_6: }\end{array}$ & 112 & 87 & 101 & 104 & 107 & 106 & 103 & 99 & 94 & 102 & $\mathrm{~dB}$ \\
\hline
\end{tabular}

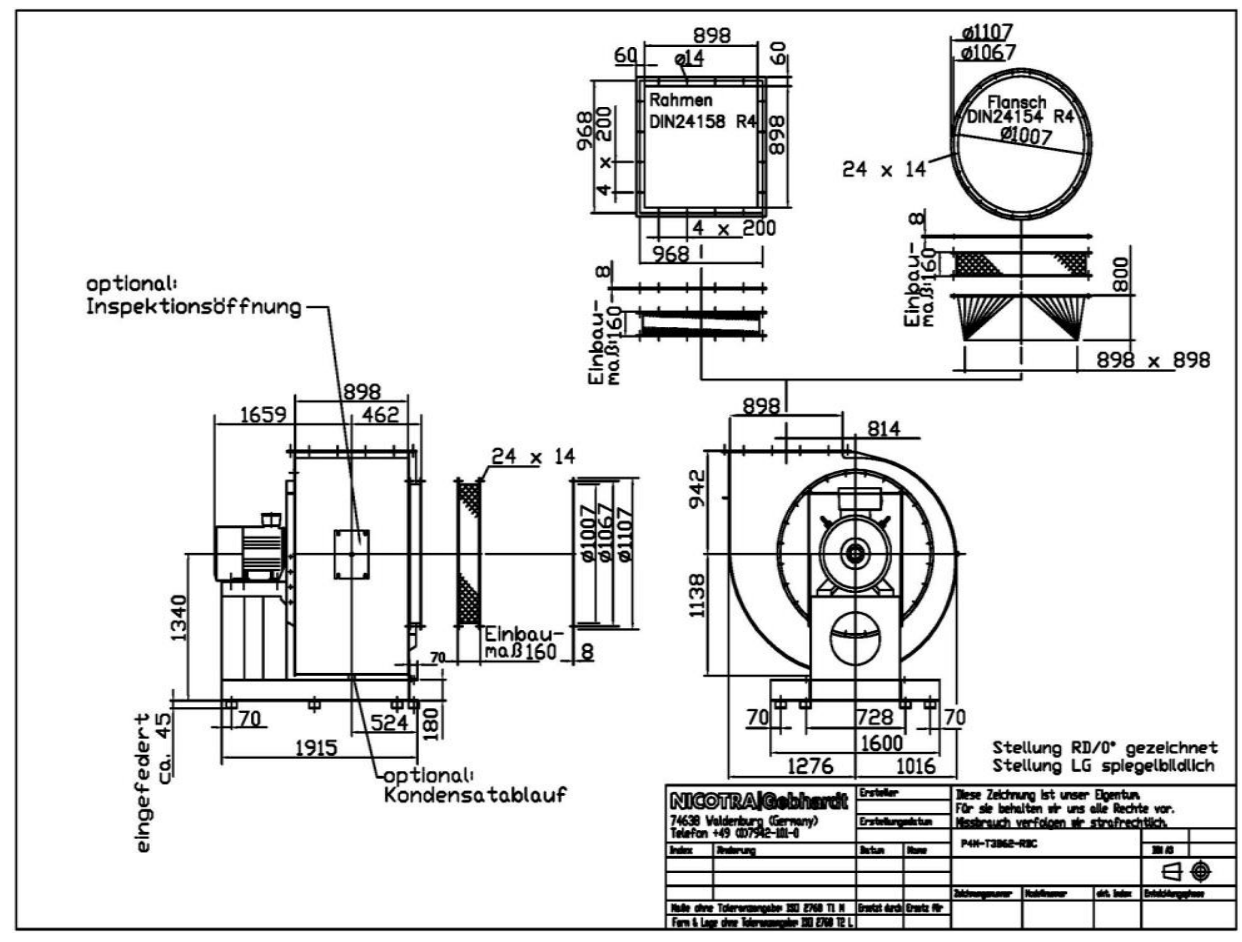

Figure 4 Drawing with built-in dimensions of the fan P4M-T3B62-RBC 


\section{DISCUSSION}

As the presented procedure for the fan selection shows, the fan selection using the specified software is quite easy when the selection criteria are known. The fan P4MT3B62-RBC belongs to a series of directdrive fans where the impeller is mounted on a shaft of electromotor. In the other process fans series, the impeller may be mounted on its own shaft with bearings where the power transmission from electromotor is carried out via a coupling or a pulley. The advan- tage of the selected fan relative to the other series is the reduced size of machine, and there is no power loss in bearings or belt transmission for the belt drive option. By selection the frequency inverter, it is possible to achieve the set operating point of the fan, i.e. precise regulation of its operation, as well as more favorable starting conditions. The selected fan works at the operating point in an optimal operating regime with high efficiency

Table 2 Technical characteristics of the fan P4M-T3B62-RBC and electromotor ACM 315M-6/HE

\begin{tabular}{|c|c|c|c|c|c|}
\hline \multicolumn{2}{|l|}{ PROCESS AIR FAN } & \multicolumn{4}{|c|}{ P4M-T3B62-RBC } \\
\hline \multicolumn{2}{|c|}{ Efficiency status (single speed motors) } & \multicolumn{4}{|c|}{ fulfills the ErP requirements 2015} \\
\hline \multicolumn{6}{|c|}{ Fan data in operating point: (warranty according to DIN 24166) } \\
\hline \multicolumn{6}{|c|}{$\begin{array}{l}\text { Offered accessory which is in contact with the transport medium can alter the characteristic } \\
\text { curve and lead to a performance reduction. }\end{array}$} \\
\hline \multicolumn{3}{|l|}{ Gas type: } & \multicolumn{3}{|c|}{ Atmospheric air } \\
\hline Air flow by inlet: & & $\mathrm{q}_{\mathrm{v}}$ & & 71632 & $\mathrm{~m}^{3} / \mathrm{h}$ \\
\hline Total pressure increase & & $\mathrm{p}_{\mathrm{F}}$ & 3706 & 3706 & $\mathrm{~Pa}$ \\
\hline Static pressure increase & & $\mathrm{p}_{\mathrm{sF}}$ & 3341 & 3341 & $\mathrm{~Pa}$ \\
\hline Pressure at inlet: & & $\mathrm{p}_{\mathrm{a}}$ & 101300 & 101300 & $\mathrm{~Pa}$ \\
\hline Density of media: & inlet & $\rho$ & 1.2 & 1.2 & $\mathrm{~kg} / \mathrm{m}^{3}$ \\
\hline Temperature media: & inlet & $\mathrm{t}$ & 35 & 20 & ${ }^{\circ} \mathrm{C}$ \\
\hline $\begin{array}{l}\text { Max. allowable media tempera- } \\
\text { ture: }\end{array}$ & inlet & $\mathrm{t}_{\max }$ & & 35 & ${ }^{\circ} \mathrm{C}$ \\
\hline Speed: & & $\mathrm{n}$ & & 1185 & $1 / \mathrm{min}$ \\
\hline Max. allowable impeller speed: & & $\mathrm{n}_{\max }$ & & 1831 & $1 / \mathrm{min}$ \\
\hline Efficiency: & at optimum & $\eta_{\text {opt }}$ & & 86 & $\%$ \\
\hline Efficiency: & $\begin{array}{l}\text { at operating } \\
\text { point }\end{array}$ & $\eta$ & & 86 & $\%$ \\
\hline Required power: & at fan shaft & $\mathrm{P}_{\mathrm{a}}$ & 86.22 & 86.22 & $\mathrm{~kW}$ \\
\hline Required power: & at motor shaft & $\mathrm{P}_{\mathrm{m}}$ & 86.22 & 86.22 & $\mathrm{~kW}$ \\
\hline Max. required power: & at motor shaft & $\mathrm{P}_{\max }$ & 87.91 & 87.91 & $\mathrm{~kW}$ \\
\hline Inertia: & at fan shaft & 1 & & 67.63 & $\mathrm{~kg}^{*} \mathrm{~m}^{2}$ \\
\hline $\begin{array}{l}\text { Start-up time by direct start, } \\
\text { calculated with Siemens-motor: }\end{array}$ & & $t_{A}$ & & 5.9 & $\mathrm{sec}$ \\
\hline \multicolumn{2}{|c|}{ Sound pressure in $1 \mathrm{~m}$ distance, free suction: } & $\mathrm{L}_{\mathrm{PA} 5}$ & 100 & 100 & $\mathrm{~dB}$ \\
\hline \multicolumn{2}{|c|}{$\begin{array}{l}\text { Sound pressure in } 1 \mathrm{~m} \text { distance, casing break out } \\
\text { (without motor) }\end{array}$} & $\mathrm{L}_{\mathrm{PA} 2}$ & 83 & 83 & $\mathrm{~dB}$ \\
\hline
\end{tabular}


MOTOR DATA

\begin{tabular}{|c|c|c|c|c|c|c|c|c|}
\hline Motor type: & \multicolumn{8}{|c|}{ Standard } \\
\hline Manufacturer: & \multicolumn{3}{|l|}{$\mathrm{AC}$} & & Type: & \multicolumn{3}{|c|}{ ACM 315 M-6/HE } \\
\hline $\begin{array}{l}\text { Degree of } \\
\text { protection: }\end{array}$ & & & IP55* & & $\begin{array}{l}\text { Mounting } \\
\text { type: }\end{array}$ & B3 & & \\
\hline Insulation class: & & & $\mathrm{F}$ & & Eff-/Temp.Cl.: & IE2 & & \\
\hline Rated power: & $\mathrm{P}_{\mathrm{mot}}$ & & 90.00 & $\mathrm{~kW}$ & & & & \\
\hline Rated speed: & $\mathrm{n}_{\mathrm{mot}}$ & & 985 & $1 / \min$ & $\begin{array}{l}\text { Weight } \\
\text { approx.: }\end{array}$ & G & 1013 & $\mathrm{~kg}$ \\
\hline Frequency: & $\mathrm{f}$ & & 50 & $\mathrm{~Hz}$ & & & & \\
\hline Voltage: & $\mathrm{U}$ & & $400 / 690$ & $\mathrm{~V}$ & Sound pressure: & $\mathrm{L}_{\mathrm{PA}}$ & 68 & $\mathrm{~dB}$ \\
\hline $\begin{array}{l}\text { Rated current } \\
\text { approx.: }\end{array}$ & 1 & by $400 \mathrm{~V}$ : & 160.00 & A & Sound power: & $\mathrm{L}_{\mathrm{WA}}$ & 82 & $\mathrm{~dB}$ \\
\hline
\end{tabular}

\begin{tabular}{|l|r|l|}
\hline ErP-data at optimum efficiency and density $\mathbf{1 . 2 0} \mathbf{~ k g} / \mathbf{m}^{\mathbf{3}}$ & & \\
\hline Measurement- / Efficiency category & B / total & \\
\hline Design status of VSD & 80.7 & $\%$ \\
\hline Overall efficiency $\left(\eta_{\text {opt }}\right)$ & 78.3 & \\
\hline Achieved efficiency grade $\left(\mathrm{N}_{\text {ist }}\right)$ & $61 / 64$ & \\
\hline Required efficiency grade in $2013 / 2015(\mathrm{~N})$ & 66837 & $\mathrm{~m}^{3} / \mathrm{h}$ \\
\hline Air flow rate $\left(\mathrm{V}_{\text {opt }}\right)$ & 3922 & $\mathrm{~Pa}$ \\
\hline Pressure rise $\left(\Delta \mathrm{p}_{\text {opt }}\right)$ & 1185 & $1 / \mathrm{min}$ \\
\hline Fan speed $\left(\mathrm{n}_{\text {vopt }}\right)$ & 90.22 & $\mathrm{~kW}$ \\
\hline Motor power input $\left(\mathrm{P}_{\text {lopt }}\right)$ & 1.039 & \\
\hline Specific ratio $\left(\mathrm{d}_{\text {dpopt }}\right)$ & & \\
\hline
\end{tabular}

\section{CONCLUSION}

Application of ProSelecta2 software significantly facilitates the designer work on a fan selection as it enables faster fan selection than selecting a fan by calculation [2], and it provides a detailed information about the selected fan in a digital format as an output. The example of fan selection in this paper does not include all the possibilities of this software that, besides the industrial process fans, enables the selection of other types of fans from the production program of Nicotra Gebhadt.

\section{REFERENCES}

[1] Catalog "Industrial Process Fans"; Nicotra Gebhardt; Issue 1.1, June 2012.

[2] B. Rajković, R. Mijović, J. Stanković: "Reconstruction of Ventilation Installation for Dust Extraction of the Primary Crushing Plant 'Veliki Krivelj“; MMI Bor, Journal "Innovations and Development", No. 1; 2012 (in Serbian) 